\title{
Changing the game - can a sport-based youth development programme generate a positive social return on investment?
}

\author{
Ben Sanders and Emanuel Raptis
}

\begin{abstract}
This study examines a sport for development and peace intervention initiated by grassroot Soccer South Africa that promotes youth employability and leadership. A results-based management approach and a social return on investment methodology were used to track the young people during and after the intervention. Preliminary results offer encouraging evidence of progress into employment, education and training with positive social returns for the youth and external stakeholders, suggesting that this investment is cost-effective and impactful. The results indicate that structured sport-based programmes can put young people to work and get them to study in a constructive manner, thereby stimulating economic growth and development. It is concluded that initiatives using sport to promote youth work merit greater investment, recognition and research.
\end{abstract}

\section{Introduction}

Sport for Development and Peace (SDP) refers to the use of sport to promote varied outcomes beyond the playing field and is defined by the Sport for Development and Peace International Working Group (SDPIWG) as the intentional use of sport, physical activity and play to attain specific development objectives in low- and middle-income countries and disadvantaged communities in high-income settings (SDPIWG 2008). SDP stakeholders working in the field and launching various initiatives over the past two decades include the United Nations, the Commonwealth, the public and the private sectors and civil society.

The 21st century saw the incorporation of sport into the mainstream development sector. Sport was widely hailed as a means of achieving the Millennium Development Goals of the United Nations (UN) (United Nations 2003b). The UN established its Inter-Agency Task Force on Sport for Development and Peace in 2002 and passed Resolution 58/5 titled "Sport as a Means to Promote Education, Health, Development and Peace" in 2003 (United Nations 2003a). At the First International Conference on Sport and Development held in Magglingen in 2003, international agencies and states signed a declaration affirming their commitment to SDP. The year 2005 was declared the International Year of Sport and Physical Education, and from 2014, April 6 has been celebrated as the International Day of Sport for Development and Peace. In a document issued by the UN (United Nations 2015), 
sport is mentioned as a tool to achieve Sustainable Development Goals, which includes the empowerment of the youth:

Sport is also an important enabler of sustainable development. We recognize the growing contribution of sport to the realization of development and peace in its promotion of tolerance and respect and the contributions it makes to the empowerment of women and of young people, individuals and communities as well as to health, education and social inclusion objectives. (United Nations 2015)

While the SDP sector has grown enormously, its impact remains debatable, partly due to a lack of rigorous research and monitoring and evaluation, limited results, unclear theories of change, and few strategies to tackle broader structural and systemic problems in development (Coakley 2011; Giulianotti 2011; Richards et al. 2013). Certain SDP programmes exhibit a gap between evidence and practice, which is often a reflection of somewhat naive and idealistic notions of the power of sport, sometimes referred to as the "Great Sport Myth". Even if sport is applied in the right manner and does result in the intended change there are deeper structural issues that may negate, or even reverse, such well-intentioned work (Sanders 2016). In a statement by the Commonwealth Advisory Body on Sport, this paradox is acknowledged as follows: "There have been instances where sport has been poorly planned, overly aligned to extremist nationalist, political or economic motives or beset by doping and corruption scandals such that a negative impact on human and social development could be argued" (Dudfield 2014, 7). Despite these criticisms, sport has the potential to foster development, especially among the youth, as it can provide mechanisms to reach young people in a "language they can understand" and engage with them on sensitive issues (e.g. HIV and AIDS) without adopting a limited traditional classroombased approach. Sport is seen as a natural and essential component of education and can function as a "school for life" by instilling values and life skills in the youth (United Nations $2003 \mathrm{~b}$ ). By its very nature, sport can function as a "youth-friendly" vehicle to engage young people in serious matters (Barkley, Sanders, and Warren 2016).

\section{Youth in South Africa}

As this study examines the effects of an SDP intervention relating to youth employability and leadership in South Africa, it is pertinent to look at the state of the youth in the country. First, it is worth taking note of the "youth bulge" in South Africa (and in other African countries). Statistics South Africa (2016) reports that 66 per cent of the total population of over 54 million are below the age of 35 years, whereas 18.5 per cent are between the ages of 10 to 19 and 24 per cent are aged between 15 and 24. While these young people are often touted as the country's future leaders, they face a range of obstacles in post-apartheid South Africa.

Youth unemployment, specifically in disadvantaged areas, remains a major issue for concern. In the second quarter of 2015, whereas the overall unemployment rate was 25 per cent (Statistics South Africa 2015), 49.9 per cent of young people aged between 15 and 24 were unemployed. Of these, 45.4 per cent were males and 55 per cent were females. These 
official figures were conservative and excluded those who had given up looking for work. The United Nations Population Fund (UNFPA 2016) claimed that, based on the 2009-2014 South African National Youth Policy's definition of youth as persons between 15 and 34 years old, almost 70 per cent of the youth were unemployed.

As such, youth unemployment, as described by South African leaders, is "a ticking time bomb". Young people, especially those from disadvantaged backgrounds, play a limited role in the South African economy. Only 33 per cent of them own businesses (UNFPA 2016) and the total early entrepreneurial activity rate is estimated to be about seven per cent (Global Entrepreneurship Monitor 2016). Furthermore, in a 2013 report it was stated that only two per cent of the working-age population was enrolled in tertiary education programmes (Centre for Development and Enterprise 2013).

South Africa's National Development Plan identifies the following two main obstacles to eliminating poverty and reducing inequality: too few South Africans are employed; and poor educational outcomes are generated by the educational system (National Planning Commission 2011). This is especially true in the case of the poor population among which many out-of-school youths and adults are unemployed. The Grassroot Soccer (GRS) youth employability and leadership programme that is reviewed in the current study is specifically designed to tackle the first obstacle directly and the second obstacle indirectly.

This study unpacks the components of the GRS programme in an effort to link specific activities to specific outcomes, and included in the study are external stakeholders that may benefit indirectly. In order to achieve this aim, the study applied the social return on investment (SROI) methodology. This involved the valuation of both inputs and outcomes (tangible and intangible) and the determination of the worth of the benefits the programme generated for society at large.

\section{Results-based management andsocial return on investment}

The Development Assistance Committee of the Organisation for Economic Co-operation and Development defines results-based management (RBM) as a "management strategy focusing on performance and achievement of outputs, outcomes and impact" (Vähämäki, Schmidt, and Molander 2011). This definition has been expanded by Meier $(2003,6)$ as follows:

RBM is a management strategy aimed at achieving important changes in the way organisations operate, with improving performance in terms of results as the central orientation. RBM provides the management framework with tools for strategic planning, risk management, performance monitoring and evaluation. Its primary purpose is to improve the efficiency and effectiveness through organisational learning, and to fulfil accountability obligations through performance reporting.

RBM, like its predecessor, the logical framework approach, depends on the conceptualisation of a plausible assumption of a results chain (Vähämäki, Schmidt, and Molander 2011). However, the main differences of RBM lie in the defined relationship 
between the terms in the results chain and the high level of RBM's contextual adaptability (Vähämäki, Schmidt, and Molander 2011).

The SROI framework builds heavily on the rationale of RBM and closely follows the approach of conceptualising a results chain built on the inputs, activities, outputs, outcomes and impact components to be analysed. The following description of SROI provided by the New Economics Foundation (Lawlor, Neitzert, and Nicholls 2008) corresponds with the above definitions of RBM:

By incorporating social, environmental and economic impacts for a range of stakeholders, [SROI] more accurately reflects the value the organisations are achieving. At the same time, it helps organisations to evidence their claims and demonstrate that specific changes are attributable to their actions.[...] SROI promotes the philosophy that measurement systems should be embedded within organisations, that they should inform strategic planning, and that those delivering services are often best placed to engage with their stakeholders and respond to new information.

SROI thus extends the focus of RBM to incorporate methods for the valuation of the social, environmental and economic benefits generated by an organisation to further strengthen its accountability obligations towards its stakeholders.

\section{Methods}

The primary purpose of this study was to use the SROI method to analyse the monetised value generated by a GRS intervention. It involved making the intangible benefits generated by the chosen programme tangible by monetising the generated outcomes and comparing the value of benefits with the value of investment in order to provide evidence (if any) of social return.

The SROI ratio entails a comparison between the value being generated by an intervention and the investment required to achieve the desired impact. However, a SROI analysis should not be restricted to one number or percentage reflecting the total return on investment, as it could be seen as a short-hand for expressing value. Rather, it should present a framework for exploring an organisation's social impact, a framework in which monetisation plays an important but not exclusive role (Lawlor, Neitzert, and Nicholls 2008). The study followed the approach recommended in the SROI guide prepared by Social Value UK (2012), and this approach consists of six stages and their corresponding phases (see Table 1). 
Table 1: The six stages and phases of the SROI method

\begin{tabular}{|l|l|}
\hline Stage 1 & Establishing scope, identifying and involving stakeholders \\
\hline Stage 2 & Mapping and valuing inputs, clarifying outputs, identifying outcomes \\
\hline Stage 3 & Evidencing and valuing outcomes \\
\hline Stage 4 & Establishing attributable impact of the intervention \\
\hline Stage 5 & Calculating SROI, performing sensitivity analysis and establishing payback period \\
\hline Stage 6 & Reporting \\
\hline
\end{tabular}

Source: Social Value UK (2012)

\section{Research setting}

The GRS youth employability and leadership programme is presented in South Africa with the aim of developing unemployed youths (volunteer coaches aged between 18 and 30) to (1) become effective change agents for improving adolescent health through training and presenting health programmes to adolescents; and (2) move on to employment, education or training following their two-year tenure with GRS.

The programme seeks to empower coaches to tackle broader societal issues, including high unemployment, poverty, gender inequality and the structural drivers of HIV and violence. GRS thus empowers young people to work as peer educators in delivering adolescent health programmes to learners and out-of-school youths in historically disadvantaged communities.

Following the International Labour Organisation's guidelines on enhancing youth employability, the programme delivers interventions aimed at improving the following skills of participants: basic and foundational skills to meet labour market needs and move on to education and training; vocational or technical skills required to perform specialised tasks; professional and personal skills related to work habits and ethics, personal integrity and honesty; and core skills such as computer literacy, creative problem-solving, active listening, group facilitation and social interaction (Brewer 2013,6). The programme organises weekly structured group sessions with participants, monthly one-on-one mentoring, annual training sessions and quarterly follow-up sessions to track progress.

\section{Stakeholders}

To identify the relevant stakeholders impacted, the potential reach of the programme was carefully considered. It was necessary to look beyond primary subjects-the coaches themselves-and consider secondary subjects impacted either positively or negatively. Based on the data collected, potential stakeholders and corresponding outcomes were either validated or discarded. Stakeholders included were deemed to be significantly impacted on by the programme, and the inclusion and exclusion of stakeholders were motivated (see 
Table 2). The exclusion of many potential stakeholders constituted a limitation of this study; thus, the findings could have reflected an underestimation of the SROI ratio.

Table 2: Stakeholders included and motivation for their inclusion

\begin{tabular}{|l|l|}
\hline Stakeholder & Motivation for inclusion \\
\hline Coaches & Primary stakeholders \\
\hline Coaches' immediate families & Dependent on coaches' income for household support \\
\hline Employers & Benefits from employable and skilled labour \\
\hline Implementing GRS staff & Income and knowledge accumulation \\
\hline Local government & $\begin{array}{l}\text { Increased tax base and less spending on social benefits and } \\
\text { employment and skills development programmes }\end{array}$ \\
\hline Educational institutions & $\begin{array}{l}\text { Improved allocation of public/private resources, higher rate of } \\
\text { timely completion and lower levels of drop-out }\end{array}$ \\
\hline
\end{tabular}

\section{Mapping the theory of change}

An impact map was established to identify all relevant inputs, activities and outputs, outcomes and indicators. The inputs directly related to the coaches corresponded to specific programme components based on the specific outcomes they aimed to achieve. Inputs related to other stakeholders not directly associated with the programme components, such as an organisation's subsidies and overheads, could still have a monetary value.

The recognised intended and unintended changes resulting from the programme guided the breakdown of specific components attributable to these changes. Specific components provided either internally or through external partners aiming to develop specific knowledge or skill sets were treated independently based on the specific outcomes these components aimed to generate.

The outcomes were related to the specific inputs and activities whereas the indicators were either related to the specific outcomes generated by those activities or to the overall intended or unintended change. The outcomes were determined objectively based on both the specific programme activities and previous programme evaluations. The subjective outcomes emerging from the data collected from the coaches tended to confirm the objective outcomes or were used to modify the objective outcomes to better correspond to the data collected. Desk-top research was used to obtain data on external stakeholders, and the outcomes reached were based on the intended or unintended changes that were presumed to occur as a result of the programme. 


\section{Establishing impact}

The method of establishing impact that was used followed the recommended approach (Social Value UK 2012) of identifying how much change there was and how long the change would last. In estimating deadweight, which refers to how much change would have occurred without the intervention, national statistics were used where possible. Information emerging from the data collection was used in some cases, and judgmentbased estimations were made in single cases. The study also considered other potential contributing factors (attribution) in the environment where the coaches resided, which were mostly estimated based on data collected and previous evaluations related to the programme. Finally, the longevity (drop-off) of the outcomes generated was for the most part given a standard deduction for estimation purposes.

\section{Data collection}

Primary and secondary data collection from stakeholders provided specific data relating to the study. A pragmatic approach was taken towards data collection with resources being allocated based on the relative importance of the stakeholder and the likelihood of obtaining the desired data.

In-depth interviews were conducted with 15 coaches. Three specific questionnaires were developed based on the current status of the coach being either employed, in education or training, or not in employment, education, or training. The immediate families of the coaches were not directly contacted; instead, relevant data was collected through interviewing the coaches. To attribute inputs and outcomes realistically, two questions with one sub-question each related directly to the impact of the programme on a family.

Key informant interviews were conducted with the programme's coordinator and monitoring and evaluation director, and the same interview questions were put to four exstaff members in the questionnaire.

Primary data collected revealed the number of coaches employed at the time of the evaluation. The value of the programme to the employers was estimated using a government wage subsidy aimed to increase employers' confidence in hiring unemployed youth. A further aim was to evaluate the ways in which coaches in employment or education provided potential benefits to the local government in that they gave inputs into the programme in the form of subsidies related to facilities where most of the programme components were implemented. Finally, the primary data collected revealed how many coaches were pursuing education or training, and this information guided estimating the quantity and duration of the potential impact. Potential impact was calculated based on desk research on the cost of providing education, the average number of students per 100,000 working-age population and a yearly drop-off estimate.

\section{Scope and limitations}

Because of the scope of the study, the components of the programme that were isolated for exploration were those focusing on generating entrepreneurial, employability, leadership, 
networking, computer and financial literacy skills, with the corresponding outcome of accessing employment, education or training (EET) after graduation. However, the study recognised that additional components relating to being a coach might be important inputs in generating intended and unintended outcomes. The study considered a range of stakeholders that could be impacted on.

GRS initiated a structured youth employability and leadership programme in 2013, and at the end of 2014 the first batch of coaches graduated from their two-year tenure. As the programme was relatively new, the current study combined both an evaluative and a forecast perspective. The time period under study was 2013-2017, with the period 2013-2015 constituting the evaluation, and 2016-2017 the forecast. It was planned to continue further follow-ups with coaches through 2016 and 2017.

To control the study's scope (which also represented a limitation), one geographical area where the programme was presented at the time of the study, namely Khayelitsha, Cape Town's largest township, was focused on.

A further limitation was the small sample of 16 coaches (of whom 15 responded). Furthermore, the data collected from them was self-reported, which could be construed as unreliable. To minimise unreliability, all interviews were conducted in the local language by a local staff member (previously a coach). To counteract potential social desirability bias caused by data being self-reported and collected by a local staff member, all interviews were conducted confidentially and coaches were made aware that participation was voluntary and that personal details would be kept confidential.

\section{Results}

The results of the evaluation are provided in terms of the SROI ratio, value per monetary unit invested, the payback period and sensitivity analysis. Whenever a verified and monetised value was not readily available, the study made use of financial proxies to account for the value either invested or generated. Financial proxies related to inputs were primarily used to value volunteer time, pro bono time provided by partners, and income foregone by coaches. Financial proxies for outcomes were used to value increase in confidence, the likelihood of future employment, the value of employability skills related to remaining employed, the value of increased health awareness, wage and stipend differences compared to minimum wage, cost of services and facilities for job searching, employee rewards, and outcomes for external stakeholders, which included employers, local government and educational institutions. Monetising outcomes can be complicated; therefore the study used the Global Value Exchange database that offers a comprehensive set of valuations relating to many outcomes.

\section{Calculating Present Value}

The calculations of present value followed standard procedures as established by Social Value UK (2012) and widely accepted methods for performing such calculations (Investopedia n.d.a.). The discount rate as determined by the South African Interbank was 
taken to be six per cent for the entire period 2013-2017 (Trading Economics n.d.), and South African Rand (ZAR) was used for all monetary figures.

\section{Present Value of Inputs}

The inputs constituted the investment portion of the programme. Since the investment was allocated over two years (2013-2014), the present value was calculated with 2013 as year zero.

$$
P V_{\text {inputs }}=\frac{326,929}{(1+0.06)}+\frac{339,203}{(1+0.06)^{2}}=\text { ZAR 610,313 }
$$

\section{Present Value of outcomes}

The outcomes were assumed to occur over the period 2013-2017. Thus, the present value of the outcomes was also calculated with 2013 as year zero.

$$
P V_{\text {outcomes }}=\frac{201,888}{(1+0.06)}+\frac{171,406}{(1+0.06)^{2}}+\frac{471,543}{(1+0.06)^{3}}+\frac{267726}{(1+0.06)^{4}}+\frac{134,379}{(1+0.06)^{5}}=\text { ZAR } 1,051,408
$$

\section{Net Present Value}

The net present value (NPV) was calculated by subtracting the present value of the inputs from the present value of the outcomes (Investopedia n.d.a.).

$$
N P V=P V_{\text {outcomes }}-P V_{\text {inputs }}=1,051,408-610,313=Z A R 441,095
$$

\section{SROIratio}

The SROI ratio was calculated using the formula recommended by Social Value UK (2012), which corresponds to the more conventional formula for calculating return on investment (Investopedia n.d.b.). The present value of the inputs ( $P V$ inputs) was deducted from the present value of the outcomes ( $P$ Voutcomes) and then divided by PVinputs to generate the SROI ratio. The SROI ratio was calculated as 72.27 per cent over the five-year period, indicating a significant social return on investment generated by the programme.

$$
S R O I=\frac{1,051,408-610,313}{610,313}=0.7227=72.27 \%
$$




\section{Value per monetary unit invested}

The value per monetary unit invested was calculated by dividing the present value of outcomes by the present value of inputs and not by subtracting the latter from the former. It was found that each ZAR invested in the progamme generated ZAR1.7227 in social value for the stakeholders included in the study.

$$
\text { Value } / \text { ZAR }=\frac{1,051,408}{610,313}=\text { ZAR } 1.7227
$$

\section{Payback Period}

Payback is considered when SROI is zero per cent, which occurred after 32 months (i.e. two years and eight months) from the start of the project (i.e. January 2013). This indicates that investments in the programme were recovered eight months after completion. During the remaining 28 months of the investigation, positive benefits were thus generated for both coaches and society at large. Because of a lack of detailed data, these benefits were estimated by treating the financial flows in year three (2015) as monthly annuities (which in all likelihood did not reflect the real situation). It was believed that, due to the front loading of income generated by coaches in the first half of 2015, payback probably occurred sometime between months 30 and 32. The SROI ratios and NPV at yearend from 2013 to 2017 are shown in Table 3.

Table 3: SROI ratios and NPV at year-end for the period 2013-2017

\begin{tabular}{|l|l|l|}
\hline Year & SROI Ratio & Net Present Value \\
\hline 2013 & $-68.79 \%$ & ZAR-419,852 \\
\hline 2014 & $-43.80 \%$ & ZAR-267,301 \\
\hline 2015 & $21.07 \%$ & ZAR128,615 \\
\hline 2016 (forecast) & $55.82 \%$ & ZAR340,680 \\
\hline 2017 (forecast) & $72.27 \%$ & ZAR441,095 \\
\hline
\end{tabular}

ZAR = South African Rand

\section{Sensitivity Analysis}

The main sensitivity consideration was to establish the share of SROI attributed to outcomes related to the coaches, which also included benefits accruing to their families. This was done to determine if the coaches generated a positive SROI in their own capacity or if benefits attributed to other stakeholders were necessary for the programme to generate a positive SROI. 


$$
S R O I_{\text {coaches }}=\frac{P V_{\text {coachoutcomes }}-P V_{\text {inputs }}}{P V_{\text {inputs }}}=0.0281=2.81 \%
$$

The sensitivity analysis revealed that the coaches generated a small positive SROI ratio in their own capacity. However, the analysis suggested that one additional coach in unemployment would result in the coaches generating a negative SROI in their own capacity. Thus, ceteris paribus, the results of the programme were considered to be the minimum target in terms of EET-related outcomes.

\section{Audit and Validity}

The study closely followed the recommendations of NEF (Lawlor, Neitzert, and Nicholls 2008) and Social Value UK (2012) regarding SROI methodology, and as such it can be considered valid. Furthermore, the checklist for SROI analysis was considered throughout the project to ensure compliance (Social Value UK 2012).

\section{Excluded Stakeholders, outcomes and Proxies}

In most cases the excluded stakeholders, although assumed to be impacted on by the programme to some degree, were not presumed to experience a material change as a result of the programme. Furthermore, the scope of the study was relatively limited, focusing on those stakeholders that were assumed to experience the highest relative change because of the programme, as well as those who could be clearly defined. Some stakeholders who provided inputs into the programme but did not experience material changes as a result of it, were excluded. Furthermore, a number of outcomes were not included in the study. In most cases, exclusion was not due to the irrelevancy of an outcome per se but to the difficulty of validating or monetising the outcome. The financial proxies used to monetise the outcomes that could not otherwise be monetised were retrieved from the Global Value Exchange database and customised to suit the South African context. Proxies requiring the use of hourly/monthly wages were based on the average wages of professions in South Africa indicated in relevant databases. In respect of the outcomes for external stakeholders, government reports and budgets were used to approximate the value.

\section{Validity, Reliability and Verification}

The validity, reliability and verification of the study's findings were assessed primarily through cross-references to previous reports and evaluations. The objective outcomes were either validated or complemented by the specific primary data collected. For those outcomes not previously considered, the Global Value Exchange database was used to choose best practice outcomes and indicators. As such, the findings were believed to be fairly valid.

\section{Discussion}

The SROI methodology has proven to be useful for evaluating previous outcomes and forecasting future outcomes relating to the GRS youth employability and leadership programme. The findings suggest that the programme can potentially provide positive 
returns for society, and show that sport can play a crucial part in the youth work profession by both engaging and capacitating the youth. SDP, in particular, has clear synergies with positive youth development.

The limitations of the study are acknowledged. The sample size used was small, but the SROI methodology used was rigorous and detailed and a number of other programme evaluations were employed. The fact that data was self-reported by coaches might affect the validity of the findings but attempts were made to ensure respondents answered truthfully and confidentially. The research had to be limited to one project location in South Africa due to time and resource constraints, but it is hoped that future studies can expand on this research. Lastly, it is acknowledged that while GRS seems to influence coaches' lives positively, there are external factors that the organisation cannot control. Thus the results of the programme, for instance, that the SROI ratio was positive and that more coaches moved on to EET, are dependent upon the number of jobs and opportunities available.

The findings of this study can be described as preliminary as they are based on forecasted future outcomes and assumptions about outcomes relating to external stakeholders. Notwithstanding that, the researchers have confidence in the method for valuing the inputs and outcomes related to the coaches and their families, the staff and volunteers as these stakeholders are within the programme's sphere of influence. Therefore the calculations provided should be viewed as fair estimations within a confidence interval rather than as definitive findings. Furthermore, the true social return on investment is believed to be significantly higher than indicated as many potential stakeholders positively impacted on by the programme were excluded from this study and the estimations were conservative.

Despite the study's limitations, it is anticipated that its findings will hold true for a wider audience and will fill a gap in both youth work and SDP literature. Persons that implement SDP or youth-led programmes tend to be regarded as inputs in a results chain rather than as beneficiaries. Therefore the effects on implementers are rarely subject to evaluation and research (Coalter 2008) even though their work determines much of the success of programmes and they may experience various outcomes as a result of their involvement. This is important to take into account in the context of youth work since implementers of SDP programmes are often youths themselves.

Furthermore, it is clear that there is great synergy between SDP initiatives aimed at the youth and youth work programmes. Sport can be a cost-effective tool for engaging young people in something they can relate to and enjoy. The concept of the youth educating the youth is common in the SDP field. Peer education allows young people to relate to a role model who can communicate with them about sensitive issues that may be too challenging for teachers, parents or health officials (Barkley, Warren, and Sanders 2016).

As indicated in the study, the positive effects of an SDP programme are not limited to programme participants-such effects may extend to peer educators. Young people trained 
as peer educators increase their skill sets and gain valuable leadership and work experience when they implement programmes, which may boost their self-esteem and reduce their vulnerability to pressures that can lead to risky behaviours (Mwaanga as cited in Levermore and Beacom 2004). Involving young people in all stages of programme design, planning, delivery and evaluation nurtures a sense of control and individual and collective responsibility and empowerment (Coalter 2013, 11). This study reinforces claims in the literature that volunteering has the effect of generating individual benefits extending beyond those resulting from the act of volunteering itself (Wilson and Musick 1999).

The benefits derived from the GRS programme have been shown to be partly the result of training and capacity building (as well as a curriculum that GRS has designed for its coaches) but also of on-the-job training and the provision of a structured work experience. Most GRS coaches get their first genuine work experience when they join the programme, and they get the opportunity to develop the skills, confidence and experience needed to progress further in employment, education or training. It is suggested that training programmes combined with hands-on experience are more likely to be effective than stand-alone training programmes.

In addition, these benefits clearly extend beyond the individual: the SROI approach demonstrates tangibly that the benefits extend to the family, broader community, government, education institutions and employers. This seems to reinforce the claim of Coalter $(2013,35)$ that the development of peer leaders, coaches and educators in SDP programmes is "a major part of the contribution of sport-in-development projects to the development of civil society."

It is important to note that outcomes among implementers or peer educators tend to be measured and judged at an individual or community level. However, the use of a SROI methodology that takes stakeholders and the broader interconnectedness and complexity of development into consideration is likely to provide a more realistic and holistic framing of the outcomes (if any) of a programme-this can show the actual contribution of an intervention to broader facets of society instead of only its contribution based on individual or anecdotal claims. Thus, while the SROI methodology may be viewed as reductionist in the sense that it seeks to monetise returns, it can be an effective results-based management approach to demonstrate the worth (or lack of worth) of an intervention. This approach may be regarded as a positive response to constant calls to address the lack of rigour and cost-effectiveness underlying many SDP and youth development initiatives, and it may appeal to the private sector and other development actors who insist on a return on investment. Admittedly, the SROI approach does not replace other research approaches and is best used alongside qualitative research and existing programme evaluations, as was done in this study.

\section{Conclusion}

The findings from the study indicate that structured sport-based programmes can put youths from historically disadvantaged backgrounds to work and get them to study in a 
constructive manner. It is recommended that the youth work profession recognises the role that sport can play in youth development, especially in the SDP field. For its part, the SDP field should engage with the youth work sector more meaningfully to determine the optimal role of sport in positive youth development, which is essential given sport's innate ability to attract and engage young people in a "youth-friendly" manner. A well-designed sport-based intervention can strengthen the fields of youth work and development. An integrated approach using sport for youth development may be a worthwhile investment and provide positive returns for society at large, including capacity building, employment, economic growth and social change. The SROI methodology and the synergies between youth development and sport for development and peace clearly merit greater investment, recognition and research. Potentially it is a winning combination. 


\section{References}

Barkley, Chris K., Jenn Warren, and Ben Sanders. 2016. More Than Just a Game: Sport as a Communication Platform in Sexuality Education for Adolescent Girls. Cape Town: Grassroot Soccer.

Brewer, Laura. 2013. "Enhancing Youth Employability: What? Why? and How? Guide to Core Work Skills." Geneva: International Labour Office. Accessed June 12, 2016. http://www.ilo.org/skills/areas/skills-for-youth-employment/WCMS_213452/lang-en/index.htm

Centre for Development and Enterprise. 2013. Graduate Unemployment in South Africa: A Much Exaggerated Problem. Johannesburg: Centre for Development and Enterprise. Accessed June 15, 2016. http://www.cde.org.za/graduate-unemployment-insouth-africa-a-much-exaggerated-problem/

Coakley, Jay. 2011. "Youth Sports: What Counts as 'Positive Development'?” Journal of Sport and Social Issues 35 (3): 1-19. https://doi.org/10.1177/0193723511417311

Coalter, Fred. 2008. "Sport-in-Development: A Monitoring and Evaluation Manual." London: UK Sport. Accessed May 2016. https://www.sportanddev.org/en/article/publication/sport-development- monitoring-andevaluation-manual

Coalter, Fred. 2013. Sport for Development: What Game Are We Playing? Abingdon-onThames, Oxford: Routledge.

Dudfield, Oliver. 2014. "Sport for Development and Peace: Opportunities, Challenges and the Commonwealth's Response." In Strengthening Sport for Development and Peace: National Policies and Strategies, edited by O. Dudfield, 1-12. London: Commonwealth Advisory Body on Sport and Commonwealth Secretariat. https://doi.org/10.14217/9781848599123-3-en

Giulianotti, Richard. 2011. "The Sport, Development and Peace Sector: A Model of Four Social Policy Domains." Journal of Social Policy 40 (4): 757-776. https://doi.org/10.1017/So047279410000930

Global Entrepreneurship Monitor. 2016. "Entrepreneurial Behaviour and Attitudes." Accessed October 10, 2016. http://www.gemconsortium.org/country-profile/108

Global Value Exchange. 2015. "Outcome Groups." Accessed October 10, 2015. http://www.globalvaluexchange.org/outcome-groups/

Investopedia. n.d.a. s.v. "Net Present Value." Accessed October 21, 2015. http://www.investopedia.com/ terms/n/npv.asp 
Investopedia. n.d.b. s.v. "Return on Investment." Accessed October 21, 2015. http://www.investopedia.com/terms/r/returnoninvestment.asp

Levermore, Roger, and Aaron Beacom, eds. 2009. Sport and International Development. Global Culture and Sport. London: Palgrave Macmillan.

Meier, Werner. 2003. "Results-Based Management: Towards a Common Understanding among Development Cooperation Agencies." Discussion Paper Version 5.0. Ottawa: Canadian International Development Agency. Accessed September $\quad 12, \quad$ 2015. $\mathrm{rg} /$ help-library/results-based-management-towards-a-commonunderstanding-among-development-cooperation

Wilson, John, and Marc Musick. 1999. "The Effects of Volunteering on the Volunteer." Law and Contemporary Problems 62 (4): 141-168. https://doi.org/10.2307/1192270 